\title{
Post-Truth Conceptual Engineering
}

\section{Manuel Gustavo Isaac*}

Swiss National Science Foundation (SNSF)

Arché Philosophical Research Centre

5 University of St Andrews

\begin{abstract}
Conceptual engineering is the method for assessing and improving our concepts. Some have recently claimed that the implementation of such method in the form of ameliorative projects is truth-driven and should thus be epistemically constrained, ultimately at least (Simion 2018b; cf. Podosky 2018). This paper challenges that claim on the assumption of a social constructionist analysis of ideologies, and provides an alternative, pragmatic and cognitive framework for determining the legitimacy of ameliorative conceptual projects overall. The upshot is that one should not ameliorate for the sake of truth or knowledge, in the case of ideologies - at least, not primarily.
\end{abstract}

Keywords. Conceptual engineering, Ameliorative project, Social constructionism, Ideologies, Post-truth.

$[\mathrm{M}] \mathrm{an}$ rests upon the merciless, the greedy, the insatiable, the murderous, in the indifference of his ignorance as if hanging in dreams upon the back of a tiger.

FRIEDRICH NieTZSCHE (1873)

\section{Introduction}

Conceptual engineering is the method for assessing and improving our concepts. ${ }^{1}$ Some have recently reiterated the claim that the implementation of such method in the form of ameliorative projects is truth-driven and should thus be constrained by epistemic considerations - be it primarily (Simion 2018b) or only ultimately (Podosky 2018). Epistemic-alethic agendas have in fact always been pretty influential among projects in conceptual engineering. ${ }^{2}$ Since Carnap (1947), Carnap (1950), and Carnap (1963) and until the most recent work by, e.g., Brigandt and Rosario (2020), Haslanger (2020), Peréz Carballo (2020), Sawyer (forthcoming), and Scharp (2020), to mention but a few. Yet, the novelty of Simion and Podosky is to have epistemic standards underpinning all-around the legitimacy of projects in conceptual engineering, and

*Address: Arché Philosophical Research Centre, University of St Andrews, 17-19 College Street, St Andrews, Fife KY16 9AL, Scotland. Email: isaac.manuelgustavo@gmail.com.

${ }^{1}$ This paper expressly assumes that conceptual engineering is about concepts, on pain of creating a misnomer otherwise, which would obviously turn the concept of conceptual engineering into a very bad case of conceptual engineering (cf. Cappelen 2018: 53, 104) — call this the "self-discrediting predicament."

${ }^{2}$ Thanks to a reviewer (this journal) for prompting me on this. 
especially, in the social world, for the latter. ${ }^{3}$ This paper challenges that stance on the assumption of a social constructionist analysis of ideologies. Social constructionism is indeed paradigmatic of ameliorative projects in conceptual engineering applied to ideological concepts at work in our social reality (e.g., Haslanger 2012). And I argue that, on the premise of the validity of a social constructionist analysis of ideologies - which I won't defend here - cognitive efficacy should replace truth and knowledge as normative standard for determining the legitimacy of ameliorative projects undertaken under the banner of conceptual engineering. Thereby, the upshot is not so much that one should (sometimes) ameliorate for non-epistemic/non-alethic aims too. Maybe most people agree on this. But rather, that one should not ameliorate for epistemic/alethic aims, in the case of ideologies - at least, not primarily. Hence, the title.

The paper goes as follows: Section 2 and 3 introduce and refine, respectively, what certainly represents the most full-fledged epistemic limiting procedure for conceptual engineering that is available in the literature to date. Section 4 shows that traditional truth-criterion and epistemic standards are ill-suited, if not wholly irrelevant, when it comes to accounting for ameliorative projects undertaken by conceptual engineering in the case of ideologies. Section 5 provides an alternative, non primarily alethic or epistemic, but instead pragmatic and cognitive framework for determining the legitimacy of ameliorative conceptual projects in general. Section 6 briefly responds to some possible objections, before Section 7 wraps up the whole argument to conclude.

\section{Alethic Engineering}

In a recent contribution to this journal, Simion (2018b: 915) starts by noting that most of the work that deals with the limits of conceptual engineering has so far only focused on the metaphysical limits of the program - that is, addressing issues such as: Can we engineer, and to what extent? - while its normative limits were then largely overlooked. The issue of the normative limits for the program of conceptual engineering concerns, not the possibility (in the sense of being feasible), but rather the need for ameliorative projects. In other words: Whether we should, provided that we could, (re-)engineer our conceptual devices, and if so, according to what kind of criterion (e.g., truth, efficacy, moral goodness, etc.)? This worry for the normative limits that may constrain the program of conceptual engineering becomes particularly pressing when one takes the method of conceptual engineering not to aim at merely fixing the deficiencies of our conceptual devices, ${ }^{4}$ but instead at improving any such devices, be they deficient or not (Simion 2018b: 918-919). In that case, indeed, one then immediately faces a wrong-kind-of-reasons problem — where a reason is said to be "of the wrong king" when, in spite of counting in favor of some action or attitude, it fails to bear on whether this action or attitude is valuable and, more specifically, has the right kind of value (Gertken and Kiesewetter 2017). This is made obvious in the following example:

\footnotetext{
${ }^{3}$ See Dutilh Novaes (2020) and Dutilh Novaes (forthcoming), however, on the social and political dimension of Carnap's explication, in line with Neurath's project of 'social engineering,' and more generally, with their shared commitment to the values of Enlightenment (cf. Carus 2007).

${ }^{4}$ Such negative characterization of the purpose of conceptual engineering - a.k.a. 'deficiency-engineering' in Koch's (2019) parlance - is commonly endorsed in the literature, both when it draws directly on Carnapian explication and more generally too (e.g., Brun 2020; Cappelen 2017; Cappelen 2018; Cappelen 2020; Dutilh Novaes 2020; Dutilh Novaes and Reck 2017; Machery 2017; Scharp 2013; Scharp 2020; Scharp and Shapiro 2017).
} 
Say that, through some weird causal chain, engineering our concept [of deer] in use so as to exclude red deer would improve the life expectancy of bumblebees, which, given that bumblebees pollinate crops, would, in turn, result in economic advantages. Should we exclude the most common type of deer from the extension of 'deer' on these counts? Should we take on the epistemic loss? Intuitively, this does not seem right. (Simion 2018b: 921)

So, "intuitively," not just any improvement justifies the application of the method of conceptual engineering to some conceptual device. Something more should be required, which Simion (2018b: 923) phrases in epistemic terms, with her so-called "Epistemic Limiting Procedure (ELP): A [conceptual device] should be ameliorated iff (1) There is all-things-considered reason to do so and (2) The amelioration does not translate into epistemic loss." 5 Importantly for our purposes (cf. Sect. 4, 5), the ELP builds on the unquestioned assumption that concepts are representational devices whose core function, qua representational devices, is an epistemic one - namely, to (accurately) represent the world (Simion 2018b: 923).

Yet, Simion's (2018) ELP has been further sophisticated. Against the requirement for knowledge preservation that underlies its correlated epistemic, representational, and ultimately truth-driven (hence, alethic) version of conceptual engineering, Podosky (2018) has indeed recently objected, also in this journal, that there are cases in which epistemic losses actually are beneficial toward the achievement of some further ends (e.g., political, social, moral). Such cases are, on Podosky's account, those of ideologies, in which some set of (presumably) detrimental concepts lead to the enactment of oppressing social structures and should as such be ameliorated, be it through their revision, elimination, or replacement (e.g., Haslanger 2012: chap. 15, 17; Haslanger 2020). ${ }^{6}$ Section 3 outlines Podosky's (2018) case for Beneficial Epistemic Losses, and the remainder of the paper draws the consequences for the limits one may want to impose to the legitimacy of conceptual engineering as ameliorative project.

\section{Beneficial Epistemic Losses}

To put it short, on Podosky's (2018) account, beneficial epistemic losses correspond to cases in which there is a practical need — be it moral, social, or political — for a temporary mismatch between a concept and the reality it represents. In other words, what we want in such cases is for a concept to provisionally be representationally inaccurate (e.g., by not carving reality at any of its joints), and therefore epistemically unsatisfying, while its representational accuracy (and epistemic satisfecit) is expected to be re-gained thanks to its alleged causal influence on the reality it (mis-)represents (Podosky 2018: 10). As already said, such cases are those of ideologies construed à la Haslanger (op. cit.) by Podosky himself, that is, as sets of corrupted representational devices (foremost among them, ideological concepts) that constitute oppressive social structures and thereby set the frame for unjust social practices and relations. According to Podosky's take on Haslangerian analyses of ideologies, ideological concepts are thus de facto representationally accurate, for they actually construct, or contribute to constructing at least, the social reality they represent. Podosky (2018: 8) states it quite clearly indeed: "[I]deology

\footnotetext{
${ }^{5}$ The ELP is formulated as operating on "representational devices" [loc. cit.] (instead of conceptual ones); for my worries concerning this terminology, see footnote 1 , as well as Sections 4 and 5.

${ }^{6}$ One can think of race talk in which, or so goes the currently fashionable view, the social race concept should replace the biological one in order to fight discrimination and advance social justice (cf. Andreasen 2020).
} 
partly constitutes social reality. Thus, ideological concepts accurately represent social reality." And as such self-fulfilling sets of representational devices, ideological concepts are both truth-

\footnotetext{
${ }^{7}$ Indeed, Simion (2018b: 924) makes herself perfectly clear on this: "Take, for instance, again, the project of engineering the concept of 'woman'. Again, say that there was nothing wrong with it from an epistemic point of view: it is a perfectly coherent concept, and, in its current shape has zero detrimental epistemic effects. Say, however, that it is morally, socially and politically defective, and it has substantive undesirable consequences for women's lives. Should we not attempt to engineer? This does not seem right. My answer to this question will lack much in the way of nuance: 'No, we shouldn't!'. Insofar as our concept of woman is epistemically perfectly functional, we should leave it be, for reasons pertaining to success in inquiry." (See Simion [2018a] for the full-length argument, and note that Podosky [2018] barely mentions this objection.)

${ }^{8}$ Actually, two cases of replacement/revision are to be considered in the fight against ideologies: Replacement/Revision of ideological, reality-constructing concepts either by non-reality-constructing concepts or by realityconstructing concepts (be they ideological, anti-ideological, or none of these). The first case results in epistemic losses in the long run, which can only be recovered by making the replacing/revised concepts to accurately represent the reality they are about — it corresponds to what (Podosky 2018: 9-10) calls "epistemic loss simpliciter." By contrast, the second case results in epistemic losses that are only provisional, and which will be recovered in virtue of the alleged causal effect the replacing/revised concepts have on the social reality they will contribute to constructing - it corresponds to what Podosky (ibid.) calls "temporary epistemic loss." This latter case is the one that is dealt with by the revised ELP. Yet, in both cases alike, epistemic standards appear ill-suited to determine all-around the legitimacy of engineering projects, for they would either be resorted to at the detriment of anti-ideological/non-ideological, non-constructive concepts or they would just become trivialized, as argued below. Thanks to a reviewer (this journal) for prompting me on this.
} 
and then Section 6 defends it against some possible objections.

\section{Power vs. Truth}

According to social constructionist takes on ideologies like the one outlined above, ideologies are self-fulfilling in the sense that the concepts which they are made of are somehow endowed with the performative power to shape, or at least to contribute to the shaping of, the social reality they are about when they are enacted into social practices and relations. Take, for instance, a sexist concept of woman that characterizes women as being better caretakers and a socio-economic system in which that concept and its associated conceptions (e.g., that women are less committed to their career or tend to forego economic success for the reward of motherhood, etc.) get enacted through an average gender wage gap of 15\% to women's detriment. Under these circumstances, when a partner in a heterosexual couple has to make adjustment in their work for child-care reasons (e.g., work part-time, take time off, etc.), it will typically be the woman. Men will thereby accrue more human capital, wealth, and power in their social and family relationships. And as a result, on a social constructionist account of phallocratic ideologies, the pattern of a "selfperpetuating economic structure that systematically disadvantages [women]" (Haslanger 2016: 123) will appear to be reinforced. The sexist concept of woman would thus have contributed to the shaping of the social reality they are about, making thereby the phallocratic ideologies they compose self-fulfilling. ${ }^{9}$

Against that background, it is then pretty obvious that ideologies fit rather poorly with a representationalist understanding of the relation between concepts and what concepts are about, for such representationalist understanding seems to critically require both the independence and the prevalence of what is represented (viz., reality) from/over what is representing it (viz., concepts) - whereas an ideological social reality results from and depends on its ideological constitution by ideological concepts, at least in part. ${ }^{10}$ Now, provided that one is willing to grant that representation requires both the independence and prevalence of the represented from/over the representing, ideological concepts cannot represent the social reality they constitute (precisely, because they constitute it). ${ }^{11}$ And if ideological concepts cannot, and a fortiori do not, represent social reality (in this regimented sense of "representation" [cf. note 11]), it would then make no sense to speak of their representational accuracy and claim, as Podosky (2018: 6) does, that "the concepts of an ideology carves [sic] social reality at the joints."

What is thus undercut by the rejection of the representationalist picture of concepts, on which concepts basically purport to provide us with true beliefs about the world when they enter, as unsaturated components, the formation of full thought contents, is the recourse to anything like a correspondence view on truth in order to account for the performative power

\footnotetext{
${ }^{9}$ This is an elaboration on Haslanger's (2016) Invisible Foot case discussed in Podosky (2018: $5 \mathrm{ff}$.).

${ }^{10}$ Podosky (2018: 10) speaks of "direction of influence," from-concept-to-world versus the other way around.

${ }^{11}$ To be clear: What is targeted with this regimentation of the notion of "representation" is only its mimetic dimension, according to which what is represented (viz., reality) is approached through some reproductive mechanism that yields a bearer which means to portray it (cf. Floridi 2011: 301). By contrast, the contentful dimension of the notion of "representation" remains untouched. And therefore, stating that ideological concepts do not represent is not tantamount to claiming that ideological concepts are contentless - as something can perfectly be contentful and non-representational at once (in this regimented sense of "representation").
} 
of ideological concepts. ${ }^{12}$ So that, when we aim at changing some ideological concepts, these are not, and shouldn't be taken as being, truthful, in the sense of being accurately representing an independent social reality; rather, they're powerful, and should be taken as such, that is, as having succeeded to shape reality so that it fulfils them; and what we want, or rather, what we should aim at, is to overthrow their power, not to debate over their representational accuracy. ${ }^{13}$ For instance, when gay right activists challenged the ideological concept HOMOSEXUAL with the slogan 'Born this way,' they were not speaking truth against the categorization of same-sex attraction as an unnatural and deviant form of sexuality. Rather, they were exhibiting gay pride as a means to claim for the social, economic, legal, etc. entitlements which same-sex couples were, and still are, deprived from (see Cantalamessa [2019], with reference to Barnes [2016] and Barnes [2017]). ${ }^{14}$ Ideology so conceived is thus not a matter of truth, but of power - that is, the power of shaping reality. And on those grounds, traditional epistemic standards, based on some alethic criterion (such as that of, e.g., truth as correspondence), appear to be utterly ill-suited, if not merely irrelevant in order to make sense of ideological concepts. ${ }^{15}$ Yet, for the purposes of conceptual engineering, this is not so problematic.

The reason why the inexpediency of traditional epistemic standards for conceptual engineering is not problematic is that very few of the concepts that we use in our everyday life and which may turn to be of concern to conceptual engineering will happen to be, pace Simion (2018b: 923) and Podosky (2018: 2, 3, 8), primarily or ultimately driven by alethic purposes, and thus primarily or ultimately responsive to epistemic standards. ${ }^{16}$ The remanent portion of truth-driven, epistemically responsive concepts will presumably be those at work in the sciences, and maybe as well in philosophy, depending on what one takes the relationship between science and philosophy to be. For example, if together with Scharp's (2020) metrological naturalism, one takes that relationship to be continuous, in that the purpose of philosophy would be that of fixing its constitutively deficient concepts (namely, by means of the method of conceptual engineering), prior to outsourcing the philosophical questions they raise to science, then one would certainly be inclined to take philosophy itself to also be truth-driven and epistemically responsive, in the sense of being based on some representational accuracy criterion. But

\footnotetext{
${ }^{12}$ NB. the notion of "truth" and its derivatives occur 9 times in Podosky (2018) (including once in a section title and twice in quoted form). Since it never comes with any sort of clarification on how to construe it, I suspect it being used rather informally, and in a not that much theory-laden way, as is typically captured by a correspondence view on truth, which takes truth to hold in the correspondence of a bearer (e.g., beliefs, mental representations, etc.) to some external item (e.g., objects, facts, state of affairs, etc.) that makes the bearer true.

${ }^{13}$ Note that Burgess and Plunkett (2013: 1094) precisely come to reject the option of relabelling their enterprise 'ethics of representation' on the ground that "the R-word seems to carry strong inflationary connotations" with respect to truth and reference, whereas what conceptual engineering is about may well not "intrinsically or essentially [be] representational in an inflationary sense."

${ }^{14}$ One can think of such 'linguistic interventions' in terms of 'communicative transformative disruptions' that aim at worldly transformations through the transgression of the normal functioning of a given language system, as "[w] hen babies started sporting onesies with I love my mommies! printed on them" (Sterken 2020).

${ }^{15}$ Note that Podosky (2018: 2) concedes the point, prior to rejecting it on no further ground than the alleged epistemic responsiveness of concepts: "Thus, one might conclude that the right kind of reason for conceptual engineering is not (always) epistemic. However, following Simion, I accept that the proper functioning of a concept is that it is responsive to epistemic reasons."

${ }^{16}$ By way of illustration, can one really think that the lay concept of tomato which groups tomatoes among vegetables is truth-driven in any respect of representational accuracy? Of course not! And yet, it is cognitively so much more efficient than the scientific (truth-driven, representationally accurate) one when the task at stake is that of cooking a salad. (For other compelling examples about lay vs. scientific concepts of whale or berry, see Chalmers [2011: 519] and Brun [2016: 1219], respectively.)
} 
that's only one option, rather idiosyncratic by the way. Now the question is: What alternative standards and criteria may suitably serve to determine the legitimacy of ameliorative projects undertaken by conceptual engineering (including ideological cases)? Section 5 develops such non-epistemic/non-alethic alternative, before we turn to some possible objections and replies in Section 6.

\section{Non-Alethic Engineering}

Let us take stock here. According to my analysis (Sect. 2-4) and contra Podosky (2018), what the case of ideologies 'constructionistically' construed shows is: That concepts of the ideological kind happen to be self-fulfilling; that, in virtue of such self-fulfilment, they debunk the basic representationalist picture to make sense of their meaning-relation to social reality; that this debunking in turn undermines the relevance of traditional (viz., correspondentist [cf. note 12]) truth criterion for ideological concepts; and thereby, that traditional epistemic standards appear to be ill-suited, if not merely irrelevant, when it comes to normatively determining the legitimacy of ameliorative projects undertaken by conceptual engineering in cases of ideologies. Here, in the case of ideologies, truth is not the right criterion, neither epistemicity the good framework to assess the cognitive quality of concepts - or to put it the other way around, in the case of ideologies, "thought can fail us without being false" (Haslanger 2012: 411). And again, this is perfectly fine, for very little of our concept-involving cognitive activities aim at enabling us to (joint-carving) know things; rather, (joint-carving) knowledge is only one among many other possible cognitive purposes for concepts to have (Nado 2019: Sect. 5). Building, as the ELP does, on the unquestioned assumption that the core function of concepts is an epistemic one - namely, to (accurately) represent the world (Simion 2018b: 923) - is thus nothing but philosophical wishful thinking. As Shields puts it in a recent manuscript:

$[\mathrm{P}]$ hilosophers have been too quick to project their own philosophical selves into these contexts. We assume that the speakers are genuinely interested in getting at the correct or best understanding of a particular concept because, as philosophers, this is the approach we would take to the exchange. ${ }^{17}$

The presumably widespread disconnection between truth-driven epistemic standards and successful concept-involving cognitive behaviour or activity in our everyday life (remember, "thought can fail us without being false" [loc. cit.]) calls for a non-alethic framework for determining the legitimacy of conceptual engineering. And a straightforward candidate is to be searched for in the very success conditions of our concept-involving cognitive behaviour and activity, and cashed out in pragmatic terms. With this in mind, after many others and against Cappelen (2018: Chap. 16), ${ }^{18}$ I propose to adopt a functionalist take on concepts for the purposes of conceptual engineering, on which concepts are taken to be some sort of devices that serve one or several purposes - serving their purposes being the concepts' function. Yet, as no

\footnotetext{
${ }^{17}$ And Shields to further flesh this idea out by contrasting philosophers' inquiry on the concept of personhood with that of "a corporate lobbyist whose motivation is to ensure that the prevailing institutional (and perhaps non-institutional) understanding of personhood is one that is most materially advantageous for the corporate sector."

${ }^{18}$ See, e.g., Eklund (2014: Sect. 2), Eklund (2015: 376), Nado (2019), Prinzing (2018: 5), Thomasson (2020), and Simion and Kelp (2020), etc. — so much so that one can even claim with Nado (2019) that functionalism is somehow, implicitly or not, the default position among conceptual engineers.
} 
one before except Machery (2017: Chap. 7), I propose to further substantiate this functionalist take in psychological terms. Let me just unpack this a bit.

Developing a full-fledged psychological understanding of the concept of concept for conceptual engineering falls beyond the scope of this paper (see ??? for more details). However, suffices to say for the present purposes that psychological theories of concepts commonly characterize them as bodies of information about some referent(s) that are retrieved by default from longterm memory in order to play a role in the cognitive processes underlying the higher cognitive competences (e.g., abstraction, categorization, induction, etc.) that are exercised to execute some higher cognitive task (e.g., language understanding, reasoning, planning, etc.) about that or these referent(s) (Machery 2009: Chap. 1). Against that background, a concept's function is the role it plays in the cognitive processes underlying the higher cognitive competences of an agent. And a functionalist take then consists in considering the primary quality measure of concepts to be a matter of efficacy, that is, of how well they fulfil their function of ultimately enabling the agent to execute the cognitive task they are used for. ${ }^{19}$ Following Nado (2019), and in contrast with anything like a 'central' or 'proper' conceptual function common to alternative versions of functionalism (cf. Haslanger 2012: 225; Thomasson 2020), the function of each concept is here taken to be both multiply instantiable, since it co-varies with the cognitive processes in which they are at work (e.g., categorization-process, etc.), and wide-ranging, since these cognitive processes underlie a broad spectrum of competences which are themselves exercised to execute a large number of higher cognitive tasks. Basically, on this account, it is the cognitive task at stake in a given cognitive context that comes to specify the concept's function - namely, the role it is meant to play in the activation of one of our higher cognitive competences.

Take, for instance, the above deer case (Sect. 2). If, in the context at stake, the conceptinvolving cognitive activity aims at preserving bumblebees or obtaining economic advantages, it will then make perfect sense, according to the present functionalist (viz., function-based, efficacy-driven) framework, to re-engineer the current (scientific) concept of deer to meet these purposes. Yet, this is not so to say that the current (scientific) concept of deer, which may well be perfectly suited for biological taxonomic purposes (among others), must be replaced all-around by its environmental or economical variant. ${ }^{20}$ But rather, that some of its alternative variants are locally better suited to serve other purposes (e.g., that of policy-making), however unadapted to classify animal species. What we will thus come to gain by replacing knowledge and truth by function and efficacy is an high flexibility in terms of calibration and context-dependence for the success condition of our concept-involving cognitive behaviours and activities - which admittedly means a much harder (and yet so much more relevant) work when implementing the method of conceptual engineering on specific case studies.

Now, such context-dependent functionalist variant of conceptual engineering may seem to face a critical situation in that it would allow for a good, that is, a cognitively efficient, concept serving a whatever bad function (e.g., morally, socially, politically, epistemically, etc.) to override a bad, that is, cognitively inefficient, concept serving a whatever good function (e.g., morally,

\footnotetext{
19 "An example here might be the 'four food groups' that many Americans of a certain age learned in primary school; that rough-and-ready method of classifying foods vastly oversimplifies the diversity of their nutritional properties, but has the benefit of being easy to learn and deploy." (Nado 2019: 15)

${ }^{20}$ Simion (2018b: 925-926) has three objections against context-dependent versions of functionalist conceptual engineering, which all ultimately boil down to some petitio principi, in that all presuppose the primacy of truth-driven epistemic responsiveness of concepts, as "[a]fter all, there is, plausibly, no such thing as inquiry-free domain."
} 
socially, politically, epistemically, etc.), and this precisely, in virtue of these concepts' cognitive efficacy - that is, in virtue of them being more or less conducive to execution of the cognitive task they are used for. Typically, in this framework, a highly oppressive ideological concept of race or gender might score better than its poorly liberating challenger within a given social reality. Two alternative solutions, however, are here easy at hand: Either to bite the bullet and claim that conceptual engineering, as methodological framework, is and should be axiologically neutral with respect to conceptual functions (and ultimately handing the decision over to the case study commissioning people - notwithstanding whatever wrong-kind-of-reason); ${ }^{21}$ or to make our functionalism for engineering projects slightly more radical and claim that re-engineering conceptual functions (i.e. assessing and improving them) also falls within the remit of conceptual engineering (Nado 2019; Thomasson 2020). Both options are perfectly sensible. But what we would have dropped anyways is the primary recourse to some truthdriven epistemic standards. ${ }^{22}$ For, as soon as conceptual efficacy gets to become the chief aim of conceptual engineering in a functionalist fashion, "truth and knowledge, by contrast, [will always only be] secondary goals at best." Here, in short: "The challenge is to generate concepts that are effective, not analyses that are true," and "[s]uccess is measured in terms of efficacy" (Nado 2019: 4, 19, 17).

\section{Objections and Replies}

In what follows, I briefly consider and respond to two possible objections to my proposal of a pragmatic and cognitive framework for determining all-around the legitimacy of conceptual engineering. Firstly, to my argument against the relevance of any alethic/epistemic framework for accounting for ideologies, which ultimately hangs on an analysis of the concept of representation (Sect. 4), one could object that representations do not necessarily imply the ontological independence and prevalence of what is represented from/over what is representing. Here, my very basic rebuttal would be that, if the concept of representation were not to involve such ontological dichotomy and hierarchy between the represented and the representing, then it should be replaced - on pain of being misleading otherwise, if only etymologically (which may obviously be taken as a conceptual defect). And I would further contend that, even if representation were not to involve the dichotomy and hierarchy under consideration, this would not mean that the correspondence view on truth, which is itself certainly at work in standard constructionist analyses of ideologies (cf. note 12), does not itself depend on such dichotomy and hierarchy (which has been shown to be ill-suited to account for ideologies [Sect. 2, 3]). Secondly, one could argue that there might be a non truth-driven epistemic framework that encompasses suitable standards for the ameliorative projects undertaken by conceptual engineering. That's perfectly fine. Yet, I would argue that, since the primacy of truth would thus have been overthrown in this framework, it would again be misleading to continue speaking of knowledge. And I would

\footnotetext{
${ }^{21}$ Cf. Dutilh Novaes (forthcoming) on the normative neutrality of Carnapian explication: "From a methodological perspective it can be viewed as an advantage, attesting to the wide applicability of [the method]."

22 Arguably, the latter case (namely, that of the radical functionalist) is less obvious in that it may seem that advocating between different competing conceptual functions, possibly "by appealing to further functions" (Nado 2019: 16), would ultimately hang on some truth-driven epistemic standards; but this would either bring us straight back to the ideology case as counter-argument (Sect. 4) or build on some kind of 'axiologic absolutism' which, as a proper case of ideology, would also bring us back to Section 4 , again, as counter-argument.
} 
therefore urge replacing epistemic talk by talk in terms of cognition (Sect. 5).

\section{Conclusion}

This paper was about the normative constraints that may limit the legitimacy of the ameliorative projects undertaken under the banner of conceptual engineering. My main claim was that, if a Halsangerian-like constructionist analysis of ideologies is to be correct, then truth and knowledge are not by themselves well suited with a view to setting up an all-around framework for normatively determining the legitimacy of ameliorative projects in conceptual engineering. With this in mind, I came to propose at last a pragmatic and cognitive alternative for developing such framework. One could obviously challenge social constructionism and its account of ideologies. In fact, neither were meant to be defended by this paper. But the validity of social constructionism bypasses the question of the normative limits of conceptual engineering. This is indeed all another story. To be left for another occasion.

\section{References}

Andreasen, Robin O. (2020). "Conceptual fragmentation and the use of 'race' in scientific theorizing". In: Shifting Concepts: The Philosophy and Psychology of Conceptual Variability. Ed. by Teresa Marques and Åsa Wikforss. Oxford: Oxford University Press. Chap. 11.

Barnes, Elizabeth (2016). The Minority Body. Oxford: Oxford University Press.

- (2017). "Realism and Social Structure". Realism and social structures 174 (10), 2417-2433.

Brigandt, Ingo and Esther Rosario (2020). "Strategic conceptual engineering for epistemic and social aims". In: Conceptual Engineering and Conceptual Ethics. Ed. by Alexis Burgess, Herman Cappelen, and David Plunkett. Oxford: Oxford University Press. Chap. 5, 100-124.

Brun, Georg (2016). "Explication as a method of conceptual re-engineering". Erkenntnis 81 (6), $1211-1241$.

- (2020). "Conceptual re-engineering: From explication to reflective equilibrium". Synthese 197 (3), 925-954.

Burgess, Alexis and David Plunkett (2013). "Conceptual ethics I". Philosophy Compass 8 (12), 1091-1101.

Cantalamessa, Elizabeth Amber (2019). "Disability studies, conceptual engineering, and conceptual activism”. Inquiry: An Interdisciplinary Journal of Philosophy, 1-31. Dor: 10 . 1080/ $0020174 X .2019 .1658630$.

Cappelen, Herman (2017). "Why philosophers shouldn't do semantics". Review of Philosophy and Psychology 8 (4), 743-762.

- (2018). Fixing Language: Conceptual Engineering and the Limits of Revision. Oxford: Oxford University Press.

- (2020). "Conceptual engineering: The Master Argument". In: Conceptual Engineering and Conceptual Ethics. Ed. by Alexis Burgess, Herman Cappelen, and David Plunkett. Oxford: Oxford University Press. Chap. 7, 132-151.

Carnap, Rudolf (1947). Meaning and Necessity: A Study in Semantics and Modal Logic. Chicago: University of Chicago Press. 
Carnap, Rudolf (1950). "On explication”. In: Logical Foundations of Probability. Chicago: University of Chicago Press. Chap. 1, 1-18.

- (1963). "Replies and systematic expositions". In: The Philosophy of Rudolf Carnap. Ed. by Paul Arthur Schilpp. La Salle: Open Court, 859-1113.

Carus, Andrew (2007). Carnap and Twentieth-Century Thought: Explication as Enlightenment. Cambridge: Cambridge University Press.

Chalmers, David John (2011). "Verbal Disputes". Philosophical Review 120 (4), 515-566.

Dutilh Novaes, Catarina (2020). "Carnapian explication and ameliorative analysis: A systematic comparison”. Synthese 197 (3), 1011-1034.

- (forthcoming). "Carnap meets Foucault: Conceptual engineering and genealogical investigations". Inquiry: An Interdisciplinary Journal of Philosophy: Special Issue 'Foundational Issues in Conceptual Engineering'. Ed. by Manuel Gustavo Isaac and Steffen Koch.

Dutilh Novaes, Catarina and Erich Reck (2017). "Carnapian explication, formalisms as cognitive tools, and the paradox of adequate formalization". Synthese 194 (1), 195-215.

Eklund, Matti (2014). "Replacing Truth?" In: Metasemantics: New Essays on the Foundations of Meaning. Ed. by Alexis Burgess and Brett Sherman. Oxford: Oxford University Press, 293-310.

- (2015). "Intuitions, conceptual engineering, and conceptual fixed points". In: The Palgrave Handbook of Philosophical Methods. Ed. by Chris Daly. Dordrecht: Springer, 363-385.

Floridi, Luciano (2011). "A defence of constructionism: Philosophy as conceptual engineering". Metaphilosophy 42 (3), 282-304.

Gertken, Jan and Benjamin Kiesewetter (2017). "The right and the wrong kind of reasons". Philosophy Compass 12 (5), 1-14. Dor: 10.1111/phc3.12412.

Haslanger, Sally Anne (2012). Resisting Reality: Social Construction and Social Critique. Oxford: Oxford University Press.

- (2016). "What is a (social) structural explanation?" Philosophical Studies 173 (1), 113-130.

- (2020). "Going on, not in the same way". In: Conceptual Engineering and Conceptual Ethics. Ed. by Alexis Burgess, Herman Cappelen, and David Plunkett. Oxford: Oxford University Press. Chap. 12, 230-260.

Koch, Steffen (2019). "Carnapian explications, experimental philosophy, and fruitful concepts". Inquiry: An Interdisciplinary Journal of Philosophy 62 (6), 700-717.

Machery, Édouard (2009). Doing without Concepts. Oxford: Oxford University Press.

- (2017). "Conceptual analysis rebooted". In: Philosophy within its Proper Bounds. Oxford: Oxford University Press. Chap. 7, 208-244.

Nado, Jennifer (2019). "Conceptual engineering, truth, and efficacy". Synthese, 1-21. Dor: 10. $1007 / \mathrm{s} 11229-019-02096-\mathrm{x}$.

Peréz Carballo, Alejandro (2020). "Conceptual evaluation: Epistemic”. In: Conceptual Engineering and Conceptual Ethics. Ed. by Alexis Burgess, Herman Cappelen, and David Plunkett. Oxford: Oxford University Press. Chap. 15, 304-332.

Podosky, Paul-Mikhail Catapang (2018). "Ideology and normativity: constraints on conceptual engineering". Inquiry: An Interdisciplinary Journal of Philosophy, 1-15. Dor: 10 . 1080/ 0020174 X.2018.1562374. 
Prinzing, Michael (2018). "The revisionist's rubric: Conceptual engineering and the discontinuity objection". Inquiry: An Interdisciplinary Journal of Philosophy 61 (8), 854-880.

Sawyer, Sarah (forthcoming). "Truth and objectivity in conceptual engineering". Inquiry: An Interdisciplinary Journal of Philosophy.

Scharp, Kevin (2013). Replacing Truth. Oxford: Oxford University Press.

- (2020). "Philosophy as the study of inconsistent concepts". In: Conceptual Engineering and Conceptual Ethics. Ed. by Alexis Burgess, Herman Cappelen, and David Plunkett. Oxford: Oxford University Press. Chap. 19, 396-416.

Scharp, Kevin and Stewart Shapiro (2017). "Revising inconsistent concepts". In: Reflections on the Liar. Ed. by Bradley Armour-Garb. Oxford: Oxford University Press, 257-280.

Simion, Mona (2018a). "Epistemic trouble for engineering 'woman'”. Logos E Episteme 9 (1), 91-98.

- (2018b). "The 'should' in conceptual engineering". Inquiry: An Interdisciplinary Journal of Philosophy 61 (8), 914-928.

Simion, Mona and Christoph Kelp (2020). "Conceptual innovation, function first". Noûs, 1-18. DOI: $10.1111 /$ nous. 12302.

Sterken, Rachel Katharine (2020). "Linguistic intervention and transformative communicative disruptions". In: Conceptual Engineering and Conceptual Ethics. Ed. by Alexis Burgess, Herman Cappelen, and David Plunkett. Oxford: Oxford University Press. Chap. 20, 417-434.

Thomasson, Amie L. (2020). "A pragmatic method for conceptual ethics". In: Conceptual Engineering and Conceptual Ethics. Ed. by Alexis Burgess, Herman Cappelen, and David Plunkett. Oxford: Oxford University Press. Chap. 21, 435-458. 